\title{
Fleece myth hints at golden age for Georgia
}

The legend of Jason and the Argonauts' heroic quest for the Golden Fleece may provide a fascinating window into real Bronze Age society, say researchers who believe they have found the earliest evidence of a trading gold mine.

The adventure, which was set about 1300 BC - a generation before the Trojan war described by Homer - involves a mission to capture the precious fleece from Colchis, in modernday Georgia. The mythological fleece has been interpreted in various ways, but is thought by some to symbolize the vast wealth and gold of Georgia.

Although gold was used and traded in ancient times, there has been scant evidence of where the precious metal used in Eurasia during the Bronze Age originated, and whether it was mined or panned from rivers. Gold mines in the Upper Nile region of Egypt and elsewhere in Africa date from 2,500 BC and are believed to have supplied the Ancient Egyptians' needs. But the legend of the Golden Fleece hints at a thriving gold trade in the Caucasus dating back further than was first thought.

In 2004, a team of German and Georgian archaeologists discovered what may be the world's oldest gold mine at Sakdrissi, about 70 kilometres southwest of Tbilisi. Thomas Stöllner and Andreas Hauptmann of Ruhr University in Bochum, Germany, and Irina Gambashidze, an archaeologist from the Centre of Archaeological Studies in Tbilisi, dated the mine to around $3000 \mathrm{BC}$.

Now, the researchers have produced evidence that suggests this mine was trading as far back as 2500 вс. The team analysed samples of gold from the mine and compared them with gold from some 25 ancient artefacts dating from 2500 to $1500 \mathrm{BC}$ in the Bronze Age. The beautifully worked pieces, housed in museum collections in Georgia and neighbouring countries, include needles, necklaces and rings. The gold was analysed using a process called LA-ICP-MS (laser ablation-inductively coupled plasma-mass

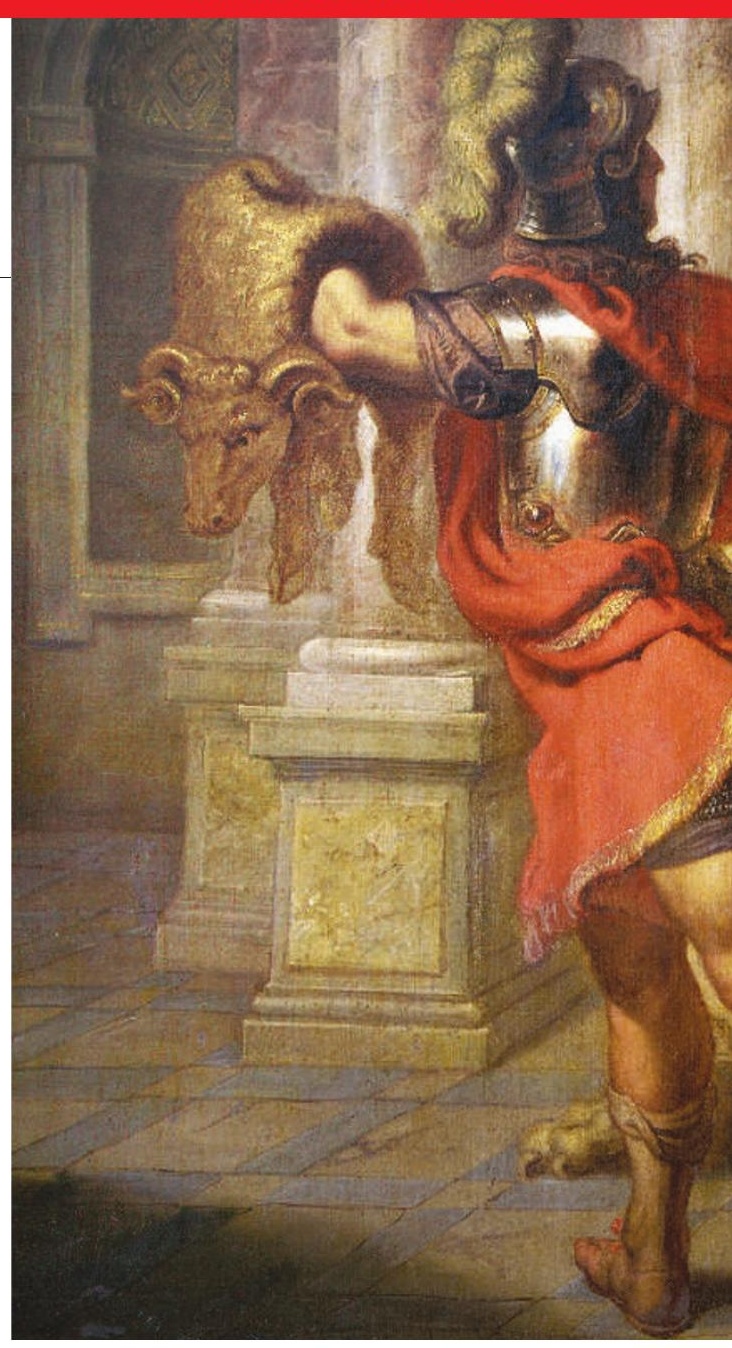

Analysis of Bronze Age artefacts, such as the lion (left), offers historical links to the Golden Fleece.

spectrometry), in which a tiny layer of surface metal is vaporized and the various elements in the vapour are identified by their mass.

\section{Journal presents a mathematical conundrum}

A branch of mathematics known as K-theory has this month seen its flagship journal bifurcate in a strange dispute, the details of which were still emerging as Nature went to press.

The events centre on Anthony Bak, a mathematician at the University of Bielefeld in Germany and until recently managing editor of the Springer journal K-Theory. Bak left the monthly journal, due, he says, to production problems and a too-high subscription rate. He has arranged to launch a rival title with another publisher that has offered a lower subscription rate, in the process shedding some editors unhappy at how the shift has been managed.

In seeking to cut prices, the editors follow the lead of the editorial board of the Elsevier mathematics journal Topology, which quit to launch a competing non-profit title (see Nature 445 , 351; 2007).

The cover date of the last issue of the supposedly monthly K-Theory was April 2006. Bak has withheld all papers accepted by the journal since then - a situation that not all of the editors, or the papers' authors, seem to have been aware of until recently.

In January 2007, the publisher sacked Bak. That month Bak wrote to his editorial board members asking them to resign en masse, which they did. As well as the cost of the journal, he mentioned production problems at Springer. But he neglected to tell Springer of the resignations. "At no point did Bak communicate to Springer directly that the board had resigned," says Catriona Byrne, editorial director for mathematics at Springer.

It was only in May that Springer learned that the board had resigned. In August, Bak announced publicly that he had arranged to launch a rival title, the Journal of K-Theory, with Cambridge University Press at a lower subscription rate. Springer has now said that it will lower the $K$-Theory subscription rate.

Eric Friedlander at Northwestern University in Evanston, Illinois, a former editor at K-Theory, is in principle sympathetic to the switch. "There is a lot of concern in the mathematics community about the cost of journals," he says. But on
17 August, Friedlander wrote to Bak to say that despite being named as a member of the editorial board of the new journal, he was not willing to serve "because I cannot endorse the process by which you have withheld manuscripts submitted to $K$-Theory and proceeded without consultation with authors and the editorial board".

One of the editors who resigned, Andrew Ranicki of the University of Edinburgh, UK, has returned to the Springer journal. He and mathematician Wolfgang Lück of the University of Münster, Germany, issued a statement on 13 August to say that they would act as interim managing editors for the journal.

Bak launched $K$-Theory in the 1980 s and ran it successfully 


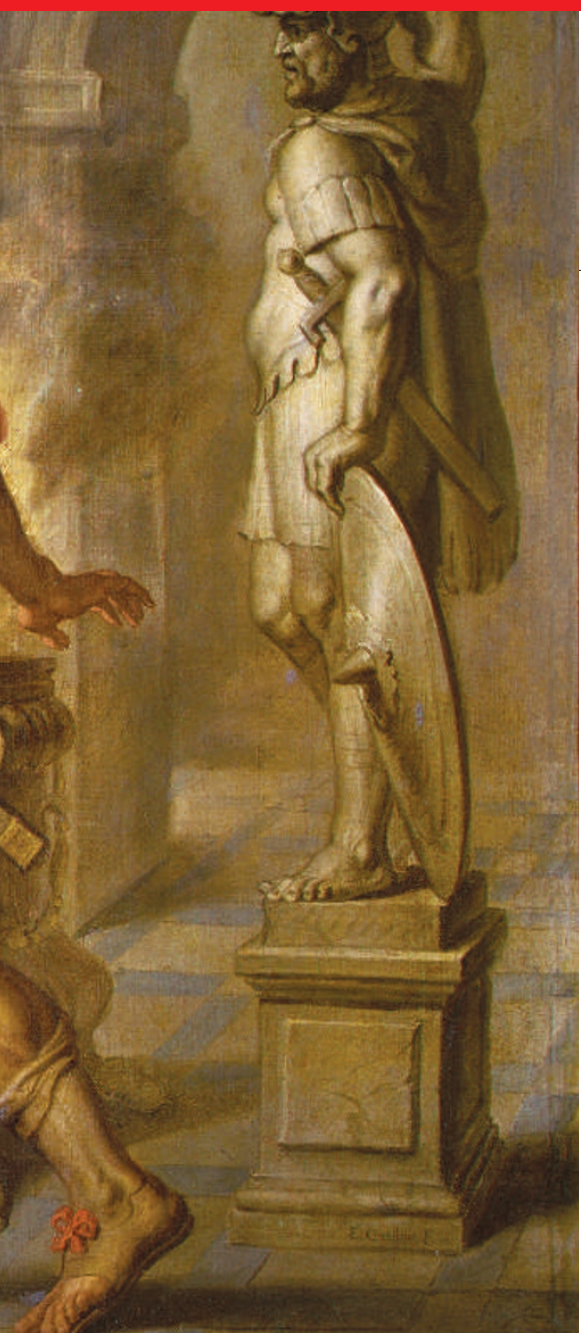

The ratio of trace elements in the gold helps to pinpoint where it came from. In this case, the team found similar levels of lead and osmium in the gold from the mine in Sakdrissi as in the artefacts. But the clincher was the unusually high amount of antimony in the artefacts, which is characteristic of the particular geochemistry at Sakdrissi.

Although this suggests a strong link between the mine and the artefacts, it is possible that the gold used was not mined, but panned from rivers in the local area. Villagers in parts of Georgia are still reported to pan the rivers for gold using sheep fleeces - another potential link to the tale of the Golden Fleece. Gold obtained from rivers tends to contain elevated levels of metals such as osmium, tin and palladium, so the archaeologists are now assessing the osmium levels in gold taken from the river to see whether the gold in the artefacts was panned or mined.

Fingerprinting gold is one of the most difficult tasks in archaeometry, says MariaFilomena Guerra, a physicist at the Centre for Research and Restoration of the Museums of France in Paris, who is separately trying to follow the gold trail. Guerra's team has been analysing gold artefacts from a Mycenaean tomb at Kazanaki near Volos, the modern Greek town close to the area where legend says Jason came from. The tomb dates from 1400 в and Guerra has so far analysed a gold-beaded necklace and gold leaf interred there, using a technique called PIXE XRF (particle-induced $\mathrm{X}$-ray emission X-ray fluorescence).

Guerra found levels of tin, platinum and palladium in the tomb samples that indicate the gold came from a river source and was almost certainly panned for, she says. She now plans further analyses to prove her hunch that the gold was panned in Georgia.

Emiliano Feresin for many years. He became increasingly unhappy after Springer acquired the journal through its merger with Kluwer Academic Publishers in 2004. Bak says that the editorial board agreed in 2004 to

\section{"There is a lot of concern in the mathematics community about the cost of journals"}

consider moving to a different publisher.

Byrne admits there were some teething problems, but says these were being or had been dealt with. She adds that Bak failed to send sufficient manuscripts to fill the journal and that those he did send arrived erratically, creating difficulties with the workflow. Bak confirms that after April 2006 he stopped sending Springer the manuscripts passed on to him by K-Theory's other editors.

Friedlander is uncomfortable that papers were held up: "Our responsibility is to review mathematics that is submitted to us and disseminate it." Lück calls it "a scandal".

Another former editor says they understood the backlog at Springer to have been so bad that the withholding of the papers would have made little difference to when they appeared. Byrne says: "This is definitely a misconception."

Lück and Ranicki have asked authors to contact them if they have papers accepted by $K$-Theory that they want to be published in the journal. Meanwhile, Bak has offered authors publication in the new Journal of K-Theory.

$\mathrm{K}$-theory, which is concerned with the algebraic properties of space, has had some high-profile moments. One major contributor to the field, Hyman Bass of the University of Michigan, received a US National Medal of Science on 27 July. But K-theory remains a relatively small discipline, which does not need more than one dedicated journal.

For this reason, Ranicki and Lück said on 17 August that they will not try to continue K-Theory, but deal only with the papers that have already been accepted.

Jenny Hogan 